\title{
A essencialidade dos serviços em bibliotecas: um olhar para o futuro?
}

\author{
The essentiality of library services: a look to the future?
}

\author{
Antonio de Souza Silva Júnior \\ Doutor em Administração \\ Universidade Federal de Pernambuco \\ silvajunior.as@gmail.c \\ Maria Vitoria Ribeiro da Silva \\ Graduanda em Biblioteconomia \\ Universidade Federal de Pernambuco \\ mv.ribeirosilva@gmail.com \\ Diego Andres Salcedo \\ Doutor em Comunicação \\ Universidade Federal de Pernambuco \\ salcedo.da@gmail.com
}

\begin{abstract}
Resumo
Este trabalho deslinda a opinião de bibliotecários acerca da essencialidade de serviços específicos oferecidos em bibliotecas, bem como do quão influentes eles acreditam ser a atualização dos serviços a serem ofertados, para acompanhamento das necessidades sociais e tecnológicas. É um trabalho de natureza exploratória e descritiva, a seleção dos serviços foi realizada por meio de levantamento bibliográfico. A partir desta seleção um questionário foi enviado para os bibliotecários, conforme contato nos sites, das 145 instituições públicas, estaduais e federais, de ensino superior brasileiras. Em seguida uma análise fatorial foi realizada. Os resultados apontaram que, embora a maioria dos respondentes considerem completamente essencial a atualização dos serviços ofertados pela biblioteca, para acompanhar a evolução social e tecnológica do passar do tempo, os maiores índices de essencialidade são atribuídos aos serviços mais comum e, em sua maioria já ofertados. Julga-se que os objetivos do trabalho foram cumpridos com assertividade; ainda que se notem agora mais perguntas que respostas, a meta inicial foi alcançada, tendo resultados demonstráveis do universo da pesquisa, conforme foi proposto.
\end{abstract}

\section{Palavras-Chave}

Serviços em bibliotecas. Análise de serviços. Gestão de bibliotecas.

\section{Abstract}

This work detaches the opinion of librarians about the essentiality of specific services offered in libraries, as well as how influential they believe to be in updating the services to be offered, to monitor social and technological needs. It is an exploratory and descriptive work, the selection of services was carried out through a bibliographic survey. From this selection, a questionnaire was sent to librarians, according to the contact on the websites of the 145 public institutions, state and federal, of higher education in Brazil. Then a factor analysis was performed. The results showed that, although the majority of respondents consider updating the services offered by the library to be completely essential, in order to keep up with the social and technological evolution over time, the highest levels of essen- 
tiality are attributed to the most common services and, in their majority, already offered. It is believed that the objectives of the work were met with assertiveness; although more questions than answers are now noticed, the initial goal was achieved, with demonstrable results from the research universe, as proposed.

\section{Keywords}

Services in libraries. Service analysis. Library management.

\section{INTRODUÇÃO}

A sociedade da informação se refere a uma construção social em que a informação ultrapassou as barreiras acadêmicas ou dos países mais industrializados, tal qual a modernização, ela progrediu de modo hegemônico, alcançando as partes mais afastadas do planeta, sendo base de quase todas as relações sociais, comerciais, políticas, econômicas e tecnológicas.

Esse contexto traz a construção de uma sociedade pautada na livre informação, todos podem dizer o que querem, quando querem e da forma que querem e que encontram apoio em suas autonomias. Um dos agentes formadores e promotores desse processo é a biblioteca, que é, historicamente, um sinônimo de informação. Sabe-se que a biblioteca já foi sinônimo de prisão de livros, de segregação de conhecimento, de guardiã de conhecimento e palco também de diversas destruições de conhecimento. Seria coerente que, no momento atual, ela fosse conhecida por sua capacidade de disseminar informação. Este fato traz o questionamento sobre a percepção da evolução do papel destas bibliotecas. Alguns as veem como fundamentalmente imutáveis, enquanto outros percebem a inovação como um dado. Há pouco consenso sobre as próximas tendências (COX; PINFIELD; RUTTER, 2019).

Enquanto Santa'anna (2016) presume que no futuro, a biblioteca ampliará suas funções deixando de ser um ambiente meramente informacional para transformar-se em espaços de convivência, Jesus e Cunha (2019) afirmam ainda que as bibliotecas podem caminhar para se tornarem, também, espaços de encontro, para o desenvolvimento de várias atividades, incluindo espaços áreas de criação, colaboração ou até atuações de inclusão no mercado de trabalho, tais como os makerspaces. $O$ que visa colaborar com as atividades científicas e acadêmicas da universidade. Isto cria um ambiente de compartilhamento e participação dos usuários

Passos e Varvakis (2017) corroboram com esta visão e dizem que em busca de atenderam as demandas dos seus usuários as bibliotecas devem se tornar mais dinâmicas, inovadoras, acessíveis, com recursos tecnológicos integrados as suas atividades, além de ser um espaço para promover experiências de aprendizado e disseminar a cultura local.

Segundo Meier (2016), as bibliotecas universitárias que estão repensando suas prioridades estratégias estão buscando ações integrativas com os projetos digitais e apoio ao ensino e pesquisa. Nestes ambientes, o papel do bibliotecário se transformou afastando o foco do desenvolvimento de coleções e fazendo referência à alfabetização e divulgação de informações. Além disso, seus líderes estão em busca de maior eficiência operacional para atender aos resultados esperados da universidade e reduzir a duplicação de esforços em suas organizações.

Contudo, as bibliotecas enfrentam dificuldades para se adaptar ao novo ambiente (FORESTI; VARVAKIS, 2019). Os autores que estudaram o futuro das bibliotecas, no final do século XX, apontavam a transição do físico para o digital, em função do avanço tecnológico, 
como o principal movimento. Todavia, o mesmo não aconteceu, nem na velocidade, nem na proporção que se imaginava, além da transição ainda não estar completa (JESUS; CUNHA, 2019 a1).

McGillis (2016) imputa aos valores tradicionais dos profissionais da área, baseado no paradigma físico, em que observa a biblioteca como um espaço tangível, como um dos responsáveis pela lenta evolução destas unidades em relação às necessidades dos seus usuários. É especificamente dentro deste cenário que se dá a proposta deste estudo, identificar a perceção dos bibliotecários, que atuam em bibliotecas públicas do ensino superior brasileiro, sobre como devem ser estes ambientes em razão das demandas futuras.

\section{SOBRE A EVOLUÇÃO DO PAPEL DA BIBLIOTECA UNIVERSITÁRIA}

Gléria e Alves Filho (2000, p. 127) defendem que bibliotecas possuem algumas funções básicas, tais como a conservação dos registros gravados, autoeducação, estímulo à leitura e difusão ativa da informação. Essas funções podem ser difíceis de serem alcançadas sem uma apropriação da biblioteca por parte dos interagentes, mas essa apropriação só vai acontecer se as bibliotecas buscarem essa interação, já que ela não é histórica nem cultural.

Considerando que biblioteca e livros, foram sinônimos durante a República Velha, essa é uma barreira persistente principalmente porque, apesar do aumento de trabalhos sobre a Sociedade da informação, ainda é insatisfatório o acesso à informação. Ainda que a informação em si possa ser acessada, de pouco vale, sem um tratamento adequado ou uma competência de uso, da qual a sociedade em geral é carente. Ou seja, para que os produtos e serviços sejam adequados é importante também entender o que os usuários precisam, quais são suas necessidades informacionais.

Rozados (2006, p. 27) explica que não há, na literatura sobre o assunto, uma definição clara para elucidar serviços de informação, mas que ela apresenta ideias sobre suas características e funções, deixando aberta uma comparação com a ideia geral da palavra serviço.

A líquida evolução das tecnologias de informação e comunicação (TIC's) tornou a disponibilização de informações mais rápida do que jamais tinha sido até então. Essas tecnologias abriram precedentes para uma transvaloração de ideias e necessidades que muda paradigmas e mexe com conceitos antes estabelecidos com muitas certezas. Esse contexto traz diversas consequências para as realidades das bibliotecas.

O paradigma da biblioteca como espaço físico para guarda, tratamento e conservação de obras continuará sendo uma realidade. Gallo-León (2016) afirma que existem coleções enormes cujo valor e possível utilidade futura leva a preservá-las. Contudo, o surgimento das coleções digitais e a disponibilização dos objetos informacionais no ciberespaço, facilitando a forma de armazenamento, tratamento, gestão e oferta de serviços e produtos biblioteconômicos são fatores que interferem na redefinição das bibliotecas atuais (SANTA'ANNA, 2016).

Dentro deste contexto, outros espaços devem ser pensados incorporando novas modalidades de aprendizagem colaborativa e interativa. Gallo-León (2016) aponta a necessidade de haver espaços pensados para a socialização. Então, em vez de ser projetado em torno do objeto do livro, por sua acomodação e acesso, ele é projetado em torno de pessoas, para facilitar o intercâmbio com a biblioteca e com outros usuários. As bibliotecas tendem a se tornarem ambientes em que os usuários se encontram para interagir, recuperar e trocar 
informação, inclusive relacionados à cultura e ao lazer (SANTA'ANNA, 2016; FORESTI; VARVAKIS, 2019).

Shen (2019) trata sobre como as bibliotecas acadêmicas podem inovar para expandir as capacidades de dados, informações e comunicação e integrar-se efetivamente ao sistema inteligente orgânico, complexo e adaptável. Assim, as novas funções transformarão as bibliotecas em bancos de testes inovadores para experimentos e explorações de dados, em base de conhecimento da comunidade e interface inteligente de informações, em um sistema de dados e informações de aprendizagem e adaptável.

Gallo-León (2016) aponta as bibliotecas acadêmicas como parceiras do aluno / pesquisador, que os ajuda em suas ferramentas e espaços para realizar suas tarefas. Para tanto, pensando em trabalho colaborativo podem ser projetados espaços para trabalho em grupo, onde podem ser ocupadas por várias pessoas ao mesmo tempo, mantendo-se os espaços individuais para estudo.

As bibliotecas podem caminhar para se tornarem também espaços para o desenvolvimento de atividades de criação, colaboração ou até atuações de inclusão no mercado de trabalho, tais como os makerspaces. $O$ que visa colaborar com as atividades científicas e acadêmicas da universidade. Isto cria um ambiente de compartilhamento e participação dos usuários (JESUS; CUNHA, 2019). Assim, podem se tornar um espaço de aprendizado experimental para os alunos, um espaço para um novo conjunto de parcerias de pesquisa e práticas pedagógicas. As bibliotecas, então, devem estar voltadas para fora, tentando apoiar o trabalho das instituições em que estão vinculadas, auxiliar seus usuários no gerenciamento de informações (SHEN, 2019; COX; PINFIELD; RUTTER, 2019).

Jesus e Cunha (2019) apontam a importante tarefa da gestão de dados de pesquisa, a biblioteca deve acompanhar de perto o desenvolvimento da pesquisa científica na sua instituição, sobretudo no que diz respeito ao armazenamento, gerenciamento, preservação e reuso dos dados gerados durante a pesquisa científica. Deixa de ser um armazenador do produto final para ser um elemento ativo do processo de criação, servindo como espaço, com ferramentas, de edição de livros e participando do processo criativo (SCHULTE et al, 2018; FORESTI; VARVAKIS, 2019). Ao estarem próximas dos pesquisadores que produzem os dados, as bibliotecas acadêmicas estão em boa posição para criar e gerenciar repositórios, compartilhando dados de pesquisa, através dos recursos digitais (TARTAROTTI; DAL'EVEDOVE, FUJITA, 2019).

A partir da digitalização total dos processos, a biblioteca pode estabelecer um novo modelo de relacionamento com o usuário. Através do uso de tecnologias que permitem o autoatendimento, além da geolocalização de obras e espaços, que podem ser consultados por meio de dispositivos móveis (GALLO-LEÓN, 2016; FORESTI; VARVAKIS, 2019).

Além disso, Jesus e Cunha (2019) assinalam que o big data fará parte do contexto da biblioteca, em que o manuseio de uma grande quantidade de dados, ou de conhecimento, será possível pela inteligência artificial disponível, um sistema que não somente fornecerá a informação, mas será inteligente o suficiente para analisar e discutir com o usuário a informação buscada.

Duarte et al (2015, p. 610) consideram que a extensa produção informacional, acentuada e ininterrupta, e o desenvolvimento de canais de comunicação têm levado a um número crescente de produtos e serviços atrelados à realidade digital, "vista a facilidade de romper barreiras geográficas para a disseminação". Estes autores explicam que:

[...] o serviço de informação em biblioteca é visto por nós como algo feito por um profissional, com vistas a atender ao interagente e dar uma direção para os 
recursos de informações de que ele necessita. Seria uma facilitação para o alcance de resultados de uma necessidade informacional. Trata-se de atender a determinada demanda, ou seja, procurar satisfazer aos interesses de informação do interagente na temática que ele procura na unidade de informação (DUARTE et al 2015, p. 608).

Através do exposto percebe-se que as atribuições de uma biblioteca vão além dos serviços oferecidos tradicionalmente por ela. Esta deve oferecer, de acordo com o seu público alvo, aquilo que visa atender às suas necessidades informacionais, o que está além da disponibilização do meio de informação. Dentro deste contexto, o foco deste estudo é identificar a perceção dos bibliotecários, que atuam em bibliotecas públicas do ensino superior brasileiro, sobre como devem ser estes ambientes em razão das demandas futuras.

\section{PROCEDIMENTOS METODOLÓGICOS}

Um estudo de caráter exploratório é realizado quando "o tema escolhido é pouco trabalhado, sendo difícil a formulação e a operacionalização de hipóteses" (OLIVEIRA, 2011, p.54). Autores como Meier (2016), Foresti e Varvakis (2019) e Jesus e Cunha (2019 a1) apontam que as bibliotecas universitárias estão buscando ações integrativas com os projetos digitais e apoio ao ensino e pesquisa e fazendo referência à alfabetização e divulgação de informações. Contudo, vêm enfrentam dificuldades para se adaptar ao novo ambiente. A ideia neste artigo é focalizar a perceção dos bibliotecários das bibliotecas universitárias das instituições federais e estaduais de ensino superior do Brasil sobre a essencialidades dos serviços das bibliotecas para atender a este contexto. Como devem ser estes ambientes em razão das demandas futuras?

Para tanto, foi realizada uma pesquisa quantitativa, que segundo Fonseca (2002) busca entender a realidade através de dados numéricos colhidos através de questionários, a serem analisados por ferramentas estatísticas, visando a relação entre variáveis. Baseado na literatura sobre serviços de bibliotecas foi identificado um total de 30 variáveis, conforme quadro 1. Um pré-teste foi realizado com 10 bibliotecários que verificaram a compreensividade do questionário preliminar. Após as sugestões, foi desenvolvido o questionário final e acompanhou um texto explicativo, tanto para apresentação, quanto para indicação da forma de resposta. Foi conferida a cada indivíduo total liberdade no momento da resposta, sendo cada resposta incluída na tabela como um índice percentual, garantindo o anonimato dos respondentes.

Quadro 1 - Lista de variáveis

\begin{tabular}{|l|}
\hline VAR1 (Acesso à internet) \\
\hline VAR2 (Acesso a multimeios) \\
\hline VAR3 (Alerta bibliográfico) \\
\hline VAR4 (Assistência por telefone) \\
\hline VAR5 (Atendimento especializado a pessoas com deficiência) \\
\hline VAR6 (Acervo para pessoas com deficiência) \\
\hline VAR7(Base de dados) \\
\hline VAR8 (Biblioterapia) \\
\hline VAR9(Canais abertos para comunicação) \\
\hline VAR10 (Consulta ao acervo) \\
\hline VAR11 (Cursos e capacitações) \\
\hline VAR12(Disponibilização de jornais atualizados) \\
\hline
\end{tabular}




\begin{tabular}{|l|}
\hline VAR13(Disponibilização de salas individuais) \\
\hline VAR14(Disseminação seletiva da informação) \\
\hline VAR15 (Empréstimo domiciliar) \\
\hline VAR16 (Espaço audiovisual) \\
\hline VAR17(Espaço para lazer) \\
\hline VAR18 (Eventos diversos) \\
\hline VAR19 (Exposições) \\
\hline VAR20 (Grupos de leitura) \\
\hline VAR21 (Oficinas) \\
\hline VAR22 (Pesquisas de usuário) \\
\hline VAR23 (Programas de alfabetização) \\
\hline VAR24(Sala para reuniões) \\
\hline VAR25(Serviço de referência) \\
\hline VAR26 (Serviço de referência virtual) \\
\hline VAR27 (Serviços de informação utilitária) \\
\hline VAR28 (Treinamentos em serviços da biblioteca) \\
\hline VAR29(Uso de redes sociais) \\
\hline VAR30(Visitas dirigidas) \\
\hline
\end{tabular}

Fonte: Dados da pesquisa (2019).

O universo ou população é o "conjunto de seres animados ou inanimados que apresentam pelo menos uma característica em comum" (MARCONI; LAKATOS, 2002, p. 41). Neste caso, o universo da pesquisa são os bibliotecários atuantes nas bibliotecas das universidades e institutos estaduais e federais. Ao todo são 145 instituições públicas, sendo 39 universidades estaduais, 68 universidades federais e 38 institutos federais, em todo o território nacional brasileiro.

A amostra que é uma "porção ou parcela, convenientemente selecionada do universo [...]; é um subconjunto do universo" (MARCONI; LAKATOS, 2002, p. 41), neste estudo foi de 237 respondentes. Foi enviado o questionário para os emails institucionais do universo, assinalados nos sites das instituições. O método aplicado foi o corte transversal, já que os objetivos da pesquisa se alinham com uma coleta de tempo determinado. A coleta foi realizada no período de 27 de maio de 2019 a 14 de junho de 2019. O percentual de respostas por Estado em relação ao total de questionários retornados foi o seguinte:

Tabela 1 - Percentual de respostas por Estados

\begin{tabular}{l|c}
\hline \multicolumn{1}{c}{ Estado } & Percentual respondentes \\
\hline Alagoas, Piauí, Mato Grosso do Sul e São Paulo & $0,4 \%$ \\
\hline Amapá e Espírito Santo & $0,8 \%$ \\
\hline Rio Grande do Norte & $1,3 \%$ \\
\hline Bahia, Minas Gerais, Sergipe e Tocantins & $1,7 \%$ \\
\hline Rondônia & $21 \%$ \\
\hline Distrito Federal e na Paraíba & $2,5 \%$ \\
\hline Ceará e Maranhão & $33 \%$ \\
\hline Paraná & $6,7 \%$ \\
\hline Goiás & $7,5 \%$ \\
\hline Pernambuco & $9,2 \%$ \\
\hline Rio Grande do Sul e Santa Catarina & $9,6 \%$ \\
\hline Rio de Janeiro & $10,5 \%$ \\
\hline Pará & $15,9 \%$ \\
\hline
\end{tabular}


Fonte: Dados da pesquisa (2019).

Uma análise fatorial exploratória foi utlizada para analisar os dados coletados. Este é um método estatístico multivariado cujo objetivo é agrupar variáveis aleatórias em grupos formados por variáveis correlacionadas. Uma vez formados, estes grupos constituem fatores. Através desta técnica é possível analisar as correlações entre as variáveis, agrupá-las em um conjunto de fatores e determinar o grau em que cada variável está ligada ao fator (CARVALHO, 2013). Assim, foi possível identificar os fatores que configuram a biblioteca, através da essencialidade dos serviços oferecidos, de acordo com a perceção dos bibliotecários.

Este método é utilizado para criar teorias nas diversas áreas do conhecimento, como componentes, correlações e ponderações relativas de uma lista de variáveis. Conforme Bezerra (2007) a análise fatorial busca, através da avaliação de um conjunto de variáveis, a identificação de dimensões de variabilidade comuns existentes, a fim de deslindar estruturas não observáveis diretamente. Assim, pode-se identificar a existência de padrões subjacentes, de modo que possam ser agrupados em um conjunto menor de dimensões; permitindo um melhor entendimento da estrutura de dados. Para tanto, utilizou-se o software SPSS 14.

\section{ANÁLISE E DISCUSSÃO DOS RESULTADOS}

Para se chegar ao resultado de uma análise fatorial é preciso atender a alguns critérios. A amostra apresenta 237 casos, indicando que o critério mínimo de observações foi respeitado segundo Hair et al (2006), pois deve ser superior a 50 observações, mas sendo aconselhável pelo menos 100 casos para uma análise mais robusta. Da mesma forma, pode ser dito a respeito da proporção do número de casos por variável, que deve ser de cinco vezes (HAIR et al, 2006). Foram 237 casos/30 variáveis, coeficiente de 7,9, estando acima do recomendado.

Também seguindo a recomendação de Hair et al (2006), as correlações com valores abaixo de 0,30 foram excluídas da análise. $O$ valor do KMO da amostra é de 0,880, superior ao patamar crítico de 0,60. Da mesma forma, o teste BTS é estatisticamente significante $(p<0,000)$. Em ambos os casos, os testes sugerem que os dados são adequados à análise fatorial. Estes resultados podem ser observados na tabela 2.

Tabela 2-KMO e Teste de Bartlett

\begin{tabular}{l|l|r}
\hline \multicolumn{2}{l}{$\begin{array}{l}\text { Kaiser-Meyer-Olkin Measure of Sampling Ade- } \\
\text { quacy (KMO). }\end{array}$} &, 880 \\
\hline $\begin{array}{l}\text { Bartlett's Test of } \\
\text { Sphericity (BTS) }\end{array}$ & Approx. Chi-Square & 1113,284 \\
\cline { 2 - 3 } & Df & 36 \\
\cline { 2 - 3 } & Sig. &, 000 \\
\hline
\end{tabular}

Fonte: Dados da pesquisa (2019).

A partir do critério de Kaiser, em que devem ser extraídos apenas fatores com valor total de eigenvalues acima de 1, pode-se extrair dois fatores: o primeiro apresenta um eigenvalue de 4,839, carregando cerca de $54 \%$ da variância. O segundo fator apresentou eigenvalue de 1,229 , carregando cerca de $14 \%$ da variância, conforme tabela 3 . Em conjunto, esses fatores explicam $68 \%$ da variância das variáveis originais. Hair et al (2006) sugerem que 
a extração deve captar, pelo menos, $60 \%$ da variância.

Tabela 3 - Total variância acumulada

\begin{tabular}{l|r|r|r|r|r|r}
\hline Component & \multicolumn{3}{|c|}{ Initial Eigenvalues } & \multicolumn{2}{c}{ Rotation Sums of Squared Loadings } \\
\hline & Total & \% Variância & Acumulado \% & Total & \% Variância & Acumulado \% \\
\hline 1 & 4,839 & 53,772 & 53,772 & 3,197 & 35,524 & 35,524 \\
\hline 2 & 1,229 & 13,655 & 67,427 & 2,871 & 31,903 & 67,427 \\
\hline 3 &, 629 & 6,987 & 74,414 & & & \\
\hline 4 &, 571 & 6,343 & 80,757 & & & \\
\hline 5 &, 494 & 5,486 & 86,243 & & & \\
\hline 6 &, 383 & 4,254 & 90,497 & & & \\
\hline 7 &, 339 & 3,767 & 94,264 & & & \\
\hline 8 &, 337 & 3,742 & 98,006 & & & \\
\hline 9 &, 179 & 1,994 & 100,000 & & & \\
\hline
\end{tabular}

Fonte: Dados da pesquisa (2019).

De acordo com Schawb (2007 apud FIGUEIREDO FILHO; SILVA JUNIOR 2010), as comunalidades representam a proporção da variância para cada variável incluída na análise que é explicada pelos componentes extraídos. O valor mínimo aceitável é de 0,50. As variáveis abaixo deste valor foram eliminadas, e a análise fatorial foi realizada novamente. A tabela 4 mostra as variáveis que atenderam a este critério.

Tabela 4 - Comunalidades

\begin{tabular}{|c|c|c|}
\hline & Inicial & Extração \\
\hline VAR6 (Acervo para pessoas com deficiência) & 1,000 & 798 \\
\hline VAR7(Base de dados) & 1,000 & 815 \\
\hline VAR9(Canais abertos para comunicação) & 1,000 & ,668 \\
\hline VAR13(Disponibilização de salas individuais) & 1,000 & ,646 \\
\hline VAR14(Disseminação seletiva da informação) & 1,000 & 675 \\
\hline VAR18 (Eventos diversos) & 1,000 & ,612 \\
\hline VAR24(Sala para reuniões) & 1,000 & 698 \\
\hline VAR25(Serviço de referência) & 1,000 &, 507 \\
\hline VAR28 (Treinamentos em serviços da biblioteca) & 1,000 & 649 \\
\hline
\end{tabular}

Fonte: Dados da pesquisa (2019).

Em seguida, forame analisadas as cargas fatoriais de cada variável em relação aos componentes extraídos. O objetivo foi identificar as variáveis que apresentam elevadas cargas fatoriais em ambos os componentes, não devendo passar de 0,40 , segundo Hair et al (2006). As variáveis que não respeitaram este requisito foram excluídas e a análise realizada novamente. A tabela 5 representa o resultado final da análise fatorial.

Tabela 5 - Matriz dos componentes de rotação

\begin{tabular}{l|r|r}
\hline & \multicolumn{2}{|c}{ Componente } \\
\hline & \multicolumn{1}{c}{1} & 2 \\
\hline VAR9(Canais abertos para comunicação) &, 749 &, 778 \\
VAR13(Disponibilização de salas individuais) &, 700 \\
VAR18 (Eventos diversos) &, 806 \\
VAR24(Sala para reuniões) &, 778 & \\
VAR28 (Treinamentos em serviços da biblioteca) &
\end{tabular}


VAR6 (Acervo para pessoas com deficiência)

VAR7(Base de dados)

VAR14(Disseminação seletiva da informação)

VAR25(Serviço de referência)

Fonte: Dados da pesquisa (2019).

Chegou-se a dois fatores que explicam $68 \%$ de como as bibliotecas das instituições públicas de ensino superior, federal e estadual, se configuram. Estes fatores foram nomeados: direcionamento dos espaços e individualização de serviços. Pode-se observar também as variáveis que compõem cada fator, sendo estas as representações dos serviços essenciais na perceção dos respondentes. Abaixo será discutido sobre cada fator.

\subsection{Direcionamento de espaços}

A análise das variáveis do primeiro fator traz a essencialidade dos serviços referentes aos espaços da biblioteca, como pode ser visto na tabela 6 .

Tabela 6 - Variáveis do fator 1

\begin{tabular}{l|c}
\hline & Componente \\
\hline & 1 \\
\hline VAR9(Canais abertos para comunicação) &, 749 \\
VAR13(Disponibilização de salas individuais) &, 778 \\
VAR18 (Eventos diversos) &, 700 \\
VAR24(Sala para reuniões) &, 806 \\
VAR28 (Treinamentos em serviços da biblioteca) &, 778 \\
\hline
\end{tabular}

Fonte: Dados da pesquisa (2019).

Este grupo trata da existência de espaços destinados a serviço de usuários, sejam espaços para comunicação, mesmo os onlines, espaço para eventos, espaços de estudo ou de mídia, bem como atividades que estimulem e ensinem os usuários a fazerem uso desses espaços.

Passos e Varvakis (2017) assinalam que as bibliotecas no futuro sejam mais dinâmicas, inovadoras, mais acessíveis e façam uso de recursos tecnológicos para prestar serviços de qualidade, criando meios para vincular experiências, habilidades e a cultura local. Isto implica na disponilização de canais abertos para comunicação, em um ambiente físico ou virtual conforme apontam Gallo-León (2016) e Foresti e Varvakis (2019).

\footnotetext{
As mídias sociais como espaço de interlocução desses estudantes passou a ter importância no processo de comunicação digital da biblioteca para que esta pudesse disseminar melhor a informação. Além disso, no aspecto físico a biblioteca universitária vem privilegiando de espaços de informação beneficiados de tecnologia que assegurem o livre acesso às ideias e oportunidade de usá-las [...] que propiciaram um ambiente de estudo aconchegante que promova 0 compartilhamento, entre a comunidade e, de modo subsequente, a liberdade de informação (VIEIRA; BAPTISTA; CERVERÓ, 2013, p. 45).
}

Os dados da pesquisa ainda indicaram a necessidade de espaços para realização de cursos e oficinas que possibilitem aos usuários a utilização independente de todos os servi- 
ços (presenciais ou virtuais) que a biblioteca oferece. Os respondentes também relataram a existência de outros espaços como essenciais, em que o desenho da biblioteca deve acomodar os usuários, contemplando espaços individuais para estudos, bem como estações de trabalho que podem ser ocupadas por várias pessoas ao mesmo tempo, pensado no trabaIho colaborativo, defendido por McGillis (2016) e Gallo-León (2016). Passos e Varvakis (2017) salientam que estes ambientes possibilitam uma aprendizagem individual e coletiva, mas ressalta a necessidade de estarem equipados com dispositivos tecnológicos mais atualizados.

Outra demanda foi a de espaços para a realização de eventos (palestras, peças, saraus etc.) pela biblioteca ou em parceria com ela, dentro do seu ambiente. Vários autores (SANTA'ANNA, 2016; GALLO-LEÓN, 2016; FORESTI; VARVAKIS, 2019) apontam esta necessidade pensando na socialização. Ambientes próprios para a realização de atividades sociais, voltadas para a cultura e o lazer.

\subsection{Individualização de serviços}

A proposta de individualização de serviços representa o segundo grupo de variáveis, conforme pode ser observada pelas variáveis da tabela 7. Esta ideia tem relação com todo o processo de vivência do usuário, conforme apontado como necessidade pelos respondentes. Todo o processo de comunicação que ocorre dentro da biblioteca deve buscar entender e atender às necessidades dos usuários.

Tabela 7 - Variáveis do fator 2

\begin{tabular}{l|c}
\hline & Componente \\
\hline VAR6 (Acervo para pessoas com deficiência) & 2 \\
VAR7(Base de dados) &, 866 \\
VAR14(Disseminação seletiva da informação) &, 873 \\
VAR25(Serviço de referência) &, 776 \\
\hline
\end{tabular}

Fonte: Dados da pesquisa (2019).

O processo de individualização dos serviços tem a ver com a aceitação e a autoresponsabilização pela individualidade do usuário mediante o serviço de informação. Par tanto, o acervo da biblioteca deve ser inserido em uma base de dados, com possibilidade de acesso para os usuários. Havendo também informação com materiais e suportes acessíveis para pessoas com deficiência, considerando cada particularidade. Além disso, com base em um perfil pré-estabelecido encaminhar as informações relevantes e notificação periódica aos usuários.

McGillis (2016) reforça a necessidade da biblioteca ter foco nas demandas e necessidades informacionais do usuário. Isto acarreta na mudança do papel do bibliotecário exigindo um maior envolvimento em todo o processo de pesquisa, incluindo gerenciamento de dados e comunicação acadêmica (MEIER, 2016; SCHULTE et al, 2018).

A tendência é que as bibliotecas promovam a criação e o compartilhamento da informação e do conhecimento na comunidade em que estão inseridas, uma vez que sua expertise é resolver problemas no gerenciamento de informações em nome de seus usuários (PASSOS e VARVAKIS, 2017;.COX; PINFIELD; RUTTER, 2019). Em função da quantidade massiva de dados Jesus e Cunha (2019) reforçam o uso da inteligência artificial para a realização desta atividade. 


\section{CONSIDERAÇÕES FINAIS}

McGillis (2016), Passos e Varvakis (2017) apontam que o foco das bibliotecas universitárias deve ser no atendimento às demandas dos seus usuários, tornando estes ambientes mais dinâmicos, inovadores, acessíveis e com recursos tecnológicos integrados as suas atividades (PASSOS; VARVAKIS, 2017).

Dentro deste contexto espaços devem ser pensados incorporando novas modalidades de aprendizagem colaborativa e interativa, tais como: espaços de socialização, cultura, lazer, atividades de criação e integrados ao projeto pedagógico, ensino e pesquisa das suas instituições (SANTA'ANNA, 2016; GALLO-LEÓN, 2016; FORESTI; VARVAKIS, 2019; SHEN, 2019; COX; PINFIELD; RUTTER, 2019).

Os dados da pesquisa apontam que a percepção dos bibliotecários de instituições superiores públicas no Brasil sobre o papel da biblioteca está apenas em parte alinhada com a literatura discutida. Dois grupos de variáveis emergiram após uma análise fatorial. $\mathrm{O}$ primeiro grupo remonta à questão dos espaços, seja físico ou virtual, destinados aos estudos individuais ou em grupo, para comunicação, eventos, bem como atividades que estimulem e ensinem os usuários a fazerem uso desses espaços. O segundo grupo trata da individualização de serviços, com foco nas necessidades dos usuários.

Este resultado ajuda a refletir sobre o exposto por Jesus e Cunha (2019 a1) em que os obstáculos enfrentados pelas bibliotecas acadêmicas no início dos anos 2000 são os mesmos com os quais a profissão está enfrentando atualmente. A mudança do paradigma físico para o digital ainda não foi superada totalmente. Pois, uma vez que os bibliotecários focam seus esforços na execução das atividades cotidianas, não participam diretamente ou não realizam discussões sobre o futuro do papel das bibliotecas.

Elementos como: parcerias com o aluno/pesquisador através de um sistema que não somente forneceria a informação, mas a analisaria e discutiria com o usuário a informação buscada; espaços para o desenvolvimento de atividades de criação, colaboração ou até atuações de inclusão no mercado de trabalho, tais como os makerspaces; integração com as práticas pedagógicas dos cursos ofertados pela instituição; e, foco em servir como espaço, com ferramentas, de edição de livros e participando do processo criativo, não surgiram nas respostas dos bibliotecários como serviços essenciais.

Esta questão tem sido estudada pelo Grupo de pesquisa METI: memória, ética, tecnologia e informação, da Universidade Federal de Pernambuco e alude ao fato de que, em larga medida, as instituições memoriais brasileiras (considerem bibliotecas, arquivos, museus e instituto de pesquisa), desconhecem ou aplicam de maneira embrionária ferramentas de planejamento estratégico e gerenciamento de projetos. Nesse sentido, pesquisa realizada em 2019 indica que bibliotecários universitários

[...] nunca tiveram experiência na atuação com gestão de projetos, além de não terem participado de treinamentos na área. A atuação dos mesmos se dá na execução das atividades rotineiras das bibliotecas, sem envolvimento na elaboração do planejamento dos projetos das instituições em que atuam. As bibliotecas não parecem estar envolvidas sobre o planejamento estratégico das instituições. Tendo os profissionais da biblioteca, a responsabilidade de executar as demandas externas solicitadas a eles. A comunicação das ações demandadas à biblioteca é realizada diretamente entre o gestor desta e a direção da instituição de ensino, sendo apenas um informativo sobre o resultado e andamento das 
atividades (SILVA JUNIOR, et al, 2020, p. 153).

Através deste estudo pode-se inferir que os maiores índices de essencialidade são atribuídos aos serviços mais comum e, em sua maioria já ofertados, na percepção dos bibliotecários a respeito do que as bibliotecas devem oferecer a seus usuários.

Considera-se que são necessárias pesquisas mais aprofundadas com perguntas mais elaboradas, de forma a entender não apenas as opiniões dos bibliotecários, mas suas fundamentações. Será que são culturais? Advém de sua formação acadêmica? É composta por processos reflexivos ou baseada em ideias cuja origem não foi investigada?

\section{REFERÊNCIAS}

BEZERRA, F. A. Análise Fatorial. In: CORRAR, Luiz; PAULO, Edilson.; DIAS FILHO, José Maria. (Orgs.) Análise multivariada para os cursos de administração, ciências contábeis e economia. São Paulo: Atlas, 2007.

CARVALHO, F. R. D. Análise Fatorial. 2013. 49 f. Dissertação (Mestrado) - Curso de Matemática, Departamento de Matemática, Universidade de Coimbra, Coimbra, 2013.

COX, A. M.; PINFIELD, S.; RUTTER, S. Academic Libraries' Stance toward the Future. Libraries and the Academy, v. 19, n. 3, p. 485-509, 2019.

DUARTE, E. J.; VIEIRA, F. S.; SILVEIRA, J. da; LOPES, A. F. L. Os serviços e os produtos de informação oferecidos pela Biblioteca Pública de Santa Catarina. Revista ACB, Florianópolis, v. 20, n. 3, p. 606-620, dez. 2015. Disponível em:

https://revista.acbsc.org.br/racb/article/view/1100/pdf. Acesso em: 31 maio 2019.

FIGUEIREDO FILHO, D. B.; SILVA JUNIOR, J. A. da. Visão além do alcance: uma introdução à análise fatorial. Opin. Publica, Campinas, v. 16, n. 1, p. 160-185, June 2010 . Disponível em: http://www.scielo.br/scielo.php?script=sci_arttext\&pid=S0104-

62762010000100007\&lng=en\&nrm=iso. Acesso em: 07 abr. 2021.

FONSECA, J. J. S. Metodologia da pesquisa científica. Fortaleza: UEC, 2002

FORESTI, F.; VARVAKIS, G. A biblioteca e o novo paradigma produtivo da indústria 4.0. Revista $A C B$, v. 24, n. 3, p. 513-535, 2019.

GALLO-LEÓN, J. La edificios para una nueva época de las bibliotecas: en el 2029 aún tendremos paredes, 2016 In: Bibliotecas 2029 : Documentos de las Jornadas "Bibliotecas 2029". Murcia: ANABAD, pp. 33-41, 2016.

GLÉRIA, C. R. Z.; ALVES FILHO, N. PSIU - Projeto de Serviços e Informações Utilitárias: relato de uma experiência na Biblioteca Pública Municipal de Londrina (PR). Informação \& Informação, Londrina, v. 5, n. 2, p. 125-137, dez. 2000. Disponível em: http://www.uel.br/revistas/uel/index.php/informacao/article/view/1668. Acesso em: 22jun. 2019. 
HAIR, J.; BLACK, W.; BABIN, B.; ANDERSON, R.; TATHAM, R. Multivariate Data Analysis. 6. ed. Upper Saddle River, NJ: Pearson Prentice Hall, 2006.

JESUS, D. L. de; CUNHA, M. B. da. A biblioteca do futuro: uma olhar em direção ao passado. Informação \& Informação, Londrina, v. 24, n. 1, p. 01 - 31, 2019.

JESUS, D. L. de; CUNHA, M. B. da. A biblioteca do futuro: uma olhar em direção ao presente. Informação \& Informação, Londrina, v. 24, n. 3, p. 311 - 334, set./dez. 2019.

MARCONI, M. de A.; LAKATOS, E. M. Técnicas de pesquisa: planejamento e execução de pesquisas, amostragens e técnicas de pesquisas, elaboração, análise e interpretação de dados. 5. ed. São Paulo: Atlas, 2002.

McGILLIS, L. The lights are on but nobody's home: the future of academic libraries? The Canadian Journal of Llibrary and Information Practice and Research, v. 11, n. 1, 2016.

MEIER, J. J. The Future of Academic Libraries: Conversations with Today's Leaders about Tomorrow. Libraries and the Academy, v. 16, n. 2, 2016, p. 263-288

OLIVEIRA, M.M. de. Como fazer projetos, relatórios, monografias, dissertações e teses. 5. ed. Rio de Janeiro: Elsevier: 2011. 197 p

PASSOS, K. G. F. dos; VARVAKIS, G. J. O futuro da Biblioteca universitária: tendências da revisão de literatura. Encontro Nacional de Pesquisa em Ciência da Informação, n. XVIII ENANCIB, 2017. Disponível em: https://brapci.inf.br/index.php/res/v/105051. Acesso em 18 de ago. 2019.

ROZADOS, H. Beatriz. Frota. A informação científica e tecnológica e os serviços de informação. Informação e Sociedade, João Pessoa, v. 16, n. 1, p. 49-62, jan. 2006. Disponível em:

https://www.lume.ufrgs.br/bitstream/handle/10183/173092/000578758.pdf?sequence=1. Acesso em: 31 de maio de 2019.

SCHULTE, J.; TIFFEN, B.; EDWARDS, J.; ABBOTT, S.; LUCA. E. Shaping the Future of Academic Libraries: authentic learning for the next generation. College \& Research Libraries, 2018. p. $685-696$.

SHEN, Y. Intelligent Infrastructure, Ubiquitous Mobility, and Smart Libraries: innovate for the future. Data Science Journal, v. 18, n. 11, 2019.

SILVA JUNIOR, A. de S.; BARROS, L. F. de; BARBOSA, D.; SALCEDO, D. A.; NAARA, I. C. A Gestão de Projetos em Bibliotecas Universitárias: análise sobre as práticas. Revista ACB, Florianópolis, v. 25, n. 1, p. 142-156, dez./mar., 2020. Disponível em: https://revista.acbsc.org.br/racb/article/view/1647. Acesso em: 17 ago. 2019. 
SANTA'ANNA, J. A redefinição da biblioteca no século XXI: de ambientes informacionais a espaços de convivência RDBCl: Rev. Digit. Bibliotecon. Cienc. Inf., v.14, n. 2, p.232-246, 2016.

TARTAROTTI, R. C.; DAL'EVEDOVE, P. R.; FUJITA, M. S. L. Biblioteconomia de dados em repositórios de pesquisa: perspectivas para a atuação bibliotecária. Informação \& Informação, Londrina, v. 24, n. 3, p. $207-226,2019$.

VIEIRA, D. V.; BAPTISTA, S. G.; CERVERÓ, A. C. As competências profissionais do bibliotecário 2.0 no espaço da biblioteca universitária: discussão da prática. Informação \& Sociedade, João Pessoa, v. 23, n. 2, p. 45-58, maio/ago. 2013. Disponível em:

https://repositorio.unb.br/handle/10482/14882. Acesso em: 19 ago. 2019. 